\title{
Statin Use Is Associated With Reduced Mortality On Mechanically Ventilated Patients: A Retrospective Propensity-Matched Analysis Of MIMIC-III Database
}

\section{Qiuhai Lin}

Emergency \& Critical Care Department, Shanghai General hospital of Shanghai Jiaotong university

Daonan Chen

Emergency \& Critical Care Department, Shanghai General Hospital of Shanghai Jiaotong University Jiyao Xu

Emergency \& Critical Care Department, Shanghai General Hospital of Shanghai Jiaotong University

\section{Congliang Miao}

Emergency \& Critical Care Department, Shanghai General Hospital of Shanghai Jiaotong University

\section{Yuan Huang}

Emergency \& Critical Care Department, Shanghai General Hospital of Shanghai Jiaotong University

\section{Liu Wang}

Emergency \& Critical Care Department, Shanghai General Hospital of Shanghai Jiaotong University

\section{Fangxia Ge}

Emergency \& Critical Care Department, Shanghai General Hospital of Shanghai Jiaotong University

\section{Mei Kang}

Clinical research center Shanghai General Hospital of Shanghai Jiaotong University

\section{Rui Tian}

Emergency \& Critical Care Department Shanghai General hospital of Shanghai Jiaotong University

\section{Yong Zhu}

Emergency \& Critical Care Department Shanghai Jiaotong University of Shanghai Jiaotong University

\section{Huifang Zhang}

Emergency \& Critical Care Department Shanghai General Hospital of Shanghai Jiaotong University

\section{Yun xie}

Emergency \& Critical Care Department, Shanghai General hospital of shanghai Jiaotong University

\section{Ruilan Wang}

Emergency \& Critical Care Department, Shanghai general hospital of Shanghai Jiaotong University

Jiang Du ( $\square$ gowindj@163.com )

critical department, Shanghai General Hospital affiliated to Shanghai Jiaotong University https://orcid.org/0000-0002-8297-5359 
Keywords: Statin, Simvastatin, Rosuvastatin, Pravastatin, Atorvastatin, Mechanical Ventilation, Lung Injury, MIMIC, Big Data

Posted Date: February 21st, 2020

DOl: https://doi.org/10.21203/rs.2.24187/v1

License: (c) (i) This work is licensed under a Creative Commons Attribution 4.0 International License. Read Full License 


\section{Abstract}

Objective: Mechanical ventilation can cause injury and inflammatory disorders in the lungs of critically ill patients. We sought to determine whether statin treatment has a protective effect on the outcome of these patients.

Methods: A retrospective observational study of ICU patients from the Medical Information Mart for Intensive Care III (MIMIC-III) database. Information on ventilated patients was analyzed using data from the MIMIC-III database. The non-statin cohort was selected using 1:1 propensity matching with the statin cohort by age, sex, severity scores and 29 other variables. Compared with nonusers, the use of statins was associated with improved 28-day survival in the unmatched cohort (HR $0.8595 \% \mathrm{Cl} 0.80 \sim 0.90)$ and matched cohort (HR $0.7295 \% \mathrm{Cl} 0.67 \sim 0.77$ ). Statin use was also associated with improved in-hospital survival in both the unmatched cohort (HR 0.90, 95\% $\mathrm{Cl} 0.85 \sim 0.95)$ and the matched cohort (HR $0.7595 \%$ $\mathrm{Cl} 0.70 \sim 0.80)$. In the multivariate Cox model, the use of statins was also associated with an improvement in 28-day survival in the unmatched cohort ( $\mathrm{HR} 0.7395 \% \mathrm{Cl} 0.68 \otimes 0.77$ ) and in the matched cohort (HR $0.7395 \% \mathrm{Cl} 0.68 \sim 0.78$ ). The use of statins was associated with longer ICU length of stay (LOS), shorter ventilator-free days (VFDs) and fewer model for end-stage liver disease score (MELD) in the matched cohort. The subgroup analysis results showed improved 28-day survival, but this improvement was not observed in patients with pneumonia, obesity, septicemia or acute respiratory failure.

Conclusions: In a population of mechanically ventilated patients, the use of statins may be associated with reduced mortality.

\section{Background}

Ventilation is a key life-saving treatment measure for critically ill patients, including patients with acute respiratory distress syndrome (ARDS), trauma, shock and other life-threatening conditions. Epidemiological data have shown that there were an estimated 790,257 hospitalizations involving mechanical ventilation in 2005 in the USA, representing 2.7 cases of mechanical ventilation per 1000 people. The estimated national associated cost was $\$ 27$ billion, representing $12 \%$ of hospital costs, which accounts for a large amount of resources in the critical care department [1]. Furthermore, ventilation can cause lung injury and lead to ventilator-associated pneumonia (VAP) and other severe complications, which may increase the mortality of critically ill patients [2]. Lung injury remains one of the major complications of mechanical ventilation in the intensive care unit (ICU). This lung injury could result from an altered host immune response after mechanical stretch. A shift toward a proinflammatory state occurs within lungs subjected to ventilation, especially if ventilation is applied to infected lungs [3]. It is greatly important to identify a medication that can modulate the altered inflammatory state after mechanical ventilation is performed on critically ill patients. Statins might have a latent capacity for lung protection. 
Statins, also known as 3-hydroxy-3 methylblycel coenzyme A (HMG-CoA) reductase inhibitors, exert pleiotropic effects in addition to their lipid-lowering effects in the context of coronary artery disease [4] and ischemic stroke [5] prophylaxes. Studies in vitro and in vivo have shown that statins can provide additional protective effects, including the reduction in inflammation, immunomodulation, antimicrobial effects, improved endothelial cell function and antithrombotic actions [6-10]. In pneumonia patients, current statin use was associated with decreased mortality ${ }^{[11]}$. Statin use or prior use may have decreased the mortality of septic patients in some observational studies [12-14]. Preliminary data from animal models have shown the protective effect on lung injury induced by sepsis [15]. Two other animal models of lung injury induced by mechanical ventilation also support these approaches $[16,17]$.

This evidence greatly increased interest in utilizing statins as a treatment and for the prevention of mechanically induced lung injury. Whether the use of statins may decrease lung injury caused by ventilation in humans is not clear. Therefore, we designed this observational study to research the potential protective effect of statin use among ventilated patients.

\section{Methods}

\section{Study design and data source}

This is a retrospective observational study. We analyzed data from a large database: Medical Information Mart for Intensive Care (MIMIC-III). The MIMIC-III database is an openly available dataset developed by the MIT Laboratory for Computational Physiology, comprising deidentified health data associated with nearly 54,000 intensive care unit admissions [18]. The data in the MIMIC-III database are composed of comprehensive clinical datasets from patients admitted to the ICUs of Beth Israel Deaconess Medical Center in Boston, MA, from June 1, 2001 to October 31, 2012. The requirement for institutional review board (IRB) approval from our institution was exempted because MIMIC-III is a third-party anonymized publicly available database with pre-existing IRB approval.

\section{Participants}

Patients who underwent mechanical ventilation were selected from the MIMIC-III database. The ventilation data were extracted from the chartvcents table. Statin usage information was extracted from the prescription table. We selected those who had taken statins before or during ventilation as the statin cohort and those who underwent ventilation without statins as the control cohort. Those who took statin medicine after extubation were excluded from this study. We included only adults in this study, so those under 18 years old were excluded. A total of 3999 patients were selected for the statin cohort. Then, we performed propensity matching by age, sex, Simplified Acute Physiology Score II (SAPSII), and 29 other variables. Each statin-exposed patient was matched with the closest corresponding nonexposed patient (that is, a patient who was not exposed to statins) at a 1:1 fixed ratio (nearest match cohort). Finally, 3717 patients were matched and included in each cohort. Detailed Postgresql and R codecs about the ventilation and statin use data are provided in the supplemental materials. 


\section{Medication exposure}

Patients who had taken statins before or during ventilation were selected as the statin cohort, and those who underwent ventilation without statins were selected as the control cohort. Patients taking statin medicine after extubation were excluded from this study. Atorvastatin, pravastatin, rosuvastatin and simvastatin were the 4 most common statin types. A total of 187 patients received atorvastatin plus simvastatin.

\section{Statistical methods}

The primary outcome was 28 -day and in-hospital all-cause mortality. The primary statistical method of comparison for the time-to-event end points was the log-rank test. A Cox proportional hazards model was used to estimate the hazard ratio (HR) of 28-day mortality and its associated $95 \%$ confidence interval (Cl). We included several variables in the model to adjust the 28-day survival (age, SAPSII score, sex, liver disease, diabetes, obesity, hypertension, etc.). The APACHE III score was not recorded for every patient, so we could not extract all APACHE III scores. The SAPSIl was chosen to represent the severity of illness. The secondary outcome analyses also included ICU LOS, hospital LOS, VFDs at 28 days and model for MELD score. Eight plasma biomarkers were extracted and studied to measure the host responses during the first 10 days after intubation. R.3.6.0 and Rstudio1.2.1335 were used to perform the statistical analyses. Some studies have reported different potencies between statins; for example, simvastatin exerted better antibacterial effects than rosuvastatin, and the latter was found to have a more potent lipid-lowering capacity $[19,20]$. Therefore, we analyzed the difference in 28-day survival among statin types in the Cox regression model. To test the efficiency of statins on patients with different profiles, we performed a subgroup analysis. Patient categorical data are presented as percentages, and continuous data are listed as means with standard deviations (SDs). We used Student's $t$ tests for continuous variables and chisquare or Fisher's exact tests for dichotomous variables.

\section{Results}

\section{Baseline results}

All 53432 cases in the MIMIC-III database were screened. A total of 24,769 individuals who had undergone ventilation met the inclusion criteria. A total of 17065 patients who had not received statin treatment were included in the nonstatin cohort. There were 3999 patients who received statin treatment before or during the ventilation time. After matching, there were 3717 patients in each cohort. They were similarities in age, sex, SAPSII and 29 more variables. The characteristics of the patients are presented in Table 1. There were 2145 cases of atorvastatin, 200 pravastatin, 171 rosuvastatin, 1284 simvastatin and 149 cases received both atorvastatin and simvastatin in the unmatched cohort. In the matched cohort, there were 1998 cases of atorvastatin, 181 pravastatin, 158 rosuvastatin, 1198 simvastatin and 135 cases received both atorvastatin plus simvastatin. 
Table 1

Baseline characteristics of the unmatched and the propensity score matched cohort

\begin{tabular}{|c|c|c|c|c|c|c|}
\hline \multirow[b]{2}{*}{ Variables } & \multicolumn{3}{|c|}{ Unmatched cohort } & \multicolumn{3}{|c|}{ Matched cohort } \\
\hline & $\begin{array}{l}\text { No Statin } \\
N=17452\end{array}$ & $\begin{array}{l}\text { Statin } \\
N=3999\end{array}$ & $\begin{array}{l}\mathrm{p}- \\
\text { value }\end{array}$ & $\begin{array}{l}\text { No Statin } \\
N=3717\end{array}$ & $\begin{array}{l}\text { Statin } \\
N=3717\end{array}$ & $\begin{array}{l}p- \\
\text { value }\end{array}$ \\
\hline \multicolumn{7}{|l|}{ Demographics } \\
\hline Age* $^{*}$ mean (SD)) & $\begin{array}{l}62.06 \\
(17.63)\end{array}$ & $\begin{array}{l}69.96 \\
(11.92)\end{array}$ & $<.001$ & $\begin{array}{l}70.48 \\
(13.42)\end{array}$ & $\begin{array}{l}69.68 \\
(12.02)\end{array}$ & 0.007 \\
\hline OASIS(mean (SD)) & $\begin{array}{l}36.61 \\
(8.39)\end{array}$ & $\begin{array}{l}35.59 \\
(8.22)\end{array}$ & $<.001$ & $\begin{array}{l}36.57 \\
(8.45)\end{array}$ & $\begin{array}{l}35.69 \\
(8.23)\end{array}$ & $\begin{array}{l}< \\
0.001\end{array}$ \\
\hline SOFA(mean (SD)) & $5.31(3.57)$ & $5.35(3.02)$ & 0.554 & $5.44(3.15)$ & $5.29(3.02)$ & 0.047 \\
\hline SAPSII* (mean (SD)) & $\begin{array}{l}39.73 \\
(15.68)\end{array}$ & $\begin{array}{l}41.04 \\
(13.39)\end{array}$ & $<.001$ & $\begin{array}{l}41.25 \\
(14.42)\end{array}$ & $\begin{array}{l}40.93 \\
(13.47)\end{array}$ & 0.333 \\
\hline Gender $^{*}=$ Male $(\%)$ & $\begin{array}{l}9967 \\
(57.1)\end{array}$ & $\begin{array}{l}2485 \\
(62.1)\end{array}$ & $<001$ & $\begin{array}{l}2201 \\
(59.2)\end{array}$ & $\begin{array}{l}2284 \\
(61.4)\end{array}$ & 0.052 \\
\hline \multicolumn{7}{|l|}{ Statin name (\%) } \\
\hline Atorvastatin & & $\begin{array}{l}2145 \\
(53.6)\end{array}$ & & & $\begin{array}{l}1998 \\
(53.8)\end{array}$ & \\
\hline $\begin{array}{l}\text { Atorvastatin + } \\
\text { Simvastatin }\end{array}$ & & 149 (3.7) & & & 135 ( 3.6$)$ & \\
\hline Pravastatin & & $200(5.0)$ & & & $181(4.9)$ & \\
\hline Rosuvastatin & & $171(4.3)$ & & & $158(4.3)$ & \\
\hline Simvastatin & & $\begin{array}{l}1284 \\
(32.1)\end{array}$ & & & $\begin{array}{l}1198 \\
(32.2)\end{array}$ & \\
\hline \multicolumn{7}{|l|}{ Commobidities } \\
\hline $\begin{array}{l}\text { Congestive heart failure } \\
*(\%)\end{array}$ & $\begin{array}{l}4573 \\
(26.2)\end{array}$ & $\begin{array}{l}1718 \\
(43.0)\end{array}$ & $<.001$ & $\begin{array}{l}1633 \\
(43.9)\end{array}$ & $\begin{array}{l}1545 \\
(41.6)\end{array}$ & 0.041 \\
\hline $\begin{array}{l}\text { Cardiac arrhythmias * } \\
(\%)\end{array}$ & $\begin{array}{l}5011 \\
(28.7)\end{array}$ & $\begin{array}{l}1849 \\
(46.2)\end{array}$ & $<.001$ & $\begin{array}{l}1709 \\
(46.0)\end{array}$ & $\begin{array}{l}1672 \\
(45.0)\end{array}$ & 0.402 \\
\hline
\end{tabular}

Continuous variables are presented as mean (standard deviation), categorical as frequency (percentage). T-test was used to compare statin recipients vs non-statin for continuous variables, Fisher's exact test for categorical variables. Standardized differences (SD) are defined as the difference in means, proportions or ranks divided by the mutual standard deviation.

$\left.{ }^{*}\right)$ variables were used for the calculation of propensity scores.

Abbreviations:LOS: length of stay; OASIS: Oxford Acute Severity of Illness Score; SOFA: Sequential Organ Failure Assessment; SAPSII: Simplified Acute Physiology Score II. 


\begin{tabular}{|c|c|c|c|c|c|c|}
\hline \multirow[b]{2}{*}{ Valvular disease * $(\%)$} & \multicolumn{3}{|c|}{ Unmatched cohort } & \multicolumn{3}{|c|}{ Matched cohort } \\
\hline & $\begin{array}{l}2561 \\
(14.7)\end{array}$ & $\begin{array}{l}1251 \\
(31.3)\end{array}$ & $<.001$ & $\begin{array}{l}1128 \\
(30.3)\end{array}$ & $\begin{array}{l}1092 \\
(29.4)\end{array}$ & 0.375 \\
\hline $\begin{array}{l}\text { Pulmonary circulation * } \\
(\%)\end{array}$ & $1253(7.2)$ & 395 ( 9.9) & $<.001$ & $355(9.6)$ & $346(9.3)$ & 0.751 \\
\hline Peripheral vascular * (\%) & 1659 ( 9.5) & 775 (19.4) & $<.001$ & $665(17.9)$ & $659(17.7)$ & 0.88 \\
\hline Other neurological * (\%) & $\begin{array}{l}2551 \\
(14.6)\end{array}$ & $482(12.1)$ & $<.001$ & $435(11.7)$ & $463(12.5)$ & 0.337 \\
\hline Chronic pulmonary * (\%) & $\begin{array}{l}3629 \\
(20.8)\end{array}$ & $962(24.1)$ & $<.001$ & $923(24.8)$ & $882(23.7)$ & 0.279 \\
\hline $\begin{array}{l}\text { Diabetes uncomplicated } \\
\star(\%)\end{array}$ & $\begin{array}{l}3184 \\
(18.2)\end{array}$ & $\begin{array}{l}1195 \\
(29.9)\end{array}$ & $<.001$ & $\begin{array}{l}1063 \\
(28.6)\end{array}$ & $\begin{array}{l}1054 \\
(28.4)\end{array}$ & 0.837 \\
\hline $\begin{array}{l}\text { Diabetes complicated * } \\
(\%)\end{array}$ & $922(5.3)$ & $415(10.4)$ & $<.001$ & $378(10.2)$ & $364(9.8)$ & 0.615 \\
\hline Hypertension * (\%) & $\begin{array}{l}8219 \\
(47.1)\end{array}$ & $\begin{array}{l}2949 \\
(73.7)\end{array}$ & $\begin{array}{l}<.001 \\
0.00\end{array}$ & $\begin{array}{l}2657 \\
(71.5)\end{array}$ & $\begin{array}{l}2675 \\
(72.0)\end{array}$ & 0.662 \\
\hline Paralysis * (\%) & $735(4.2)$ & $193(4.8)$ & 0.093 & $180(4.8)$ & $181(4.9)$ & 1 \\
\hline Hypothyroidism * (\%) & $1538(8.8)$ & $469(11.7)$ & $<.001$ & $449(12.1)$ & $426(11.5)$ & 0.428 \\
\hline Renal failure * (\%) & $\begin{array}{l}2112 \\
(12.1)\end{array}$ & $800(20.0)$ & $<.001$ & $699(18.8)$ & $696(18.7)$ & 0.953 \\
\hline Liver disease * (\%) & $\begin{array}{l}1843 \\
(10.6)\end{array}$ & $108(2.7)$ & $\hat{0}_{0.001}$ & $87(2.3)$ & $108(2.9)$ & 0.147 \\
\hline Peptic ulcer * (\%) & $16(0.1)$ & $1(0.0)$ & 0.298 & $0(0.0)$ & $1(0.0)$ & 1 \\
\hline Lymphoma * $(\%)$ & 339 ( 1.9$)$ & $39(1.0)$ & $<.001$ & $36(1.0)$ & $38(1.0)$ & 0.907 \\
\hline Metastatic cancer * $(\%)$ & $1092(6.3)$ & 78 ( 2.0) & $\begin{array}{l}< \\
0.001\end{array}$ & $72(1.9)$ & $78(2.1)$ & 0.68 \\
\hline Solid tumor * $(\%)$ & $990(5.7)$ & $111(2.8)$ & $<.001$ & $107(2.9)$ & $106(2.9)$ & 1 \\
\hline \multicolumn{7}{|c|}{$\begin{array}{l}\text { Continuous variables are presented as mean (standard deviation), categorical as frequency } \\
\text { (percentage). T-test was used to compare statin recipients vs non-statin for continuous variables, } \\
\text { Fisher's exact test for categorical variables. Standardized differences (SD) are defined as the } \\
\text { difference in means, proportions or ranks divided by the mutual standard deviation. }\end{array}$} \\
\hline \multicolumn{7}{|c|}{${ }^{(*}$ )variables were used for the calculation of propensity scores. } \\
\hline $\begin{array}{l}\text { Abbreviations:LOS: lengt } \\
\text { Organ Failure Assessme }\end{array}$ & $\begin{array}{l}\text { stay; OAS } \\
\text { APSII: Sim }\end{array}$ & $\begin{array}{l}\text { xford Acl } \\
\text { ed Acute }\end{array}$ & $\begin{array}{l}\text { verity } \\
\text { Jlogy }\end{array}$ & $\begin{array}{l}\text { Illness S } \\
\text { ore II. }\end{array}$ & OFA: Se & \\
\hline
\end{tabular}




\begin{tabular}{|c|c|c|c|c|c|c|}
\hline \multirow[b]{2}{*}{$\begin{array}{l}\text { Rheumatoid arthritis * } \\
(\%)\end{array}$} & \multicolumn{3}{|c|}{ Unmatched cohort } & \multicolumn{3}{|c|}{ Matched cohort } \\
\hline & 459 ( 2.6$)$ & 103 ( 2.6) & 0.889 & $123(3.3)$ & $101(2.7)$ & 0.154 \\
\hline Coagulopathy * (\%) & $\begin{array}{l}2499 \\
(14.3)\end{array}$ & $520(13.0)$ & 0.033 & $447(12.0)$ & $458(12.3)$ & 0.723 \\
\hline Obesity * (\%) & $1033(5.9)$ & $448(11.2)$ & $\begin{array}{l}< \\
0.001\end{array}$ & $363(9.8)$ & $374(10.1)$ & 0.698 \\
\hline Weight loss * $(\%)$ & $957(5.5)$ & $122(3.1)$ & $<.001$ & $120(3.2)$ & 119 (3.2) & 1 \\
\hline Fluid electrolyte * (\%) & $\begin{array}{l}5840 \\
(33.5)\end{array}$ & $\begin{array}{l}1230 \\
(30.8)\end{array}$ & 0.001 & $\begin{array}{l}1116 \\
(30.0)\end{array}$ & $\begin{array}{l}1140 \\
(30.7)\end{array}$ & 0.562 \\
\hline Blood loss anemia * (\%) & $353(2.0)$ & $60(1.5)$ & 0.035 & $66(1.8)$ & $56(1.5)$ & 0.411 \\
\hline Deficiency anemias * $(\%)$ & $\begin{array}{l}2907 \\
(16.7)\end{array}$ & $968(24.2)$ & $\begin{array}{l}< \\
0.001\end{array}$ & $820(22.1)$ & $834(22.4)$ & 0.717 \\
\hline Alcohol abuse * (\%) & $1732(9.9)$ & $135(3.4)$ & $\hat{0}_{0.001}$ & $109(2.9)$ & $133(3.6)$ & 0.133 \\
\hline Drug abuse * $(\%)$ & $803(4.6)$ & $50(1.3)$ & $<0.001$ & $40(1.1)$ & $50(1.3)$ & 0.34 \\
\hline Psychoses * (\%) & $756(4.3)$ & $126(3.2)$ & 0.001 & $107(2.9)$ & 119 (3.2) & 0.457 \\
\hline Depression * $(\%)$ & $1354(7.8)$ & $315(7.9)$ & 0.826 & $272(7.3)$ & $291(7.8)$ & 0.43 \\
\hline Top diagnoses* (\%) & & & $<.001$ & & & 0.992 \\
\hline Bone Fracture & $1173(6.7)$ & 78 ( 2.0) & & $76(2.0)$ & $78(2.1)$ & \\
\hline Cerebral infarction & $206(1.2)$ & $129(3.2)$ & & $121(3.3)$ & $121(3.3)$ & \\
\hline Coronary Artery Disorder & $944(5.4)$ & $865(21.6)$ & & 712 (19.2) & $744(20.0)$ & \\
\hline Heart Failure & $423(2.4)$ & $171(4.3)$ & & $192(5.2)$ & $167(4.5)$ & \\
\hline Hemorrhage & $881(5.0)$ & 93 ( 2.3) & & $94(2.5)$ & $93(2.5)$ & \\
\hline Infection & $487(2.8)$ & $74(1.9)$ & & $69(1.9)$ & $74(2.0)$ & \\
\hline
\end{tabular}

Continuous variables are presented as mean (standard deviation), categorical as frequency (percentage). T-test was used to compare statin recipients vs non-statin for continuous variables, Fisher's exact test for categorical variables. Standardized differences (SD) are defined as the difference in means, proportions or ranks divided by the mutual standard deviation.

$\left.{ }^{*}\right)$ variables were used for the calculation of propensity scores.

Abbreviations:LOS: length of stay; OASIS: Oxford Acute Severity of Illness Score; SOFA: Sequential Organ Failure Assessment; SAPSII: Simplified Acute Physiology Score II. 


\begin{tabular}{|c|c|c|c|c|}
\hline \multirow[b]{2}{*}{ Intracranial Hemorrhage } & \multicolumn{2}{|c|}{ Unmatched cohort } & \multicolumn{2}{|c|}{ Matched cohort } \\
\hline & $791(4.5)$ & 79 ( 2.0) & $85(2.3)$ & $79(2.1)$ \\
\hline Kidney Failure & $109(0.6)$ & $22(0.6)$ & $24(0.6)$ & $22(0.6)$ \\
\hline Liver Disease & $606(3.5)$ & $6(0.2)$ & $4(0.1)$ & $6(0.2)$ \\
\hline Misc & $\begin{array}{l}6920 \\
(39.7)\end{array}$ & $761(19.0)$ & $790(21.3)$ & $761(20.5)$ \\
\hline Myocardial Infarction & 635 (3.6) & $551(13.8)$ & $448(12.1)$ & $464(12.5)$ \\
\hline Nalignant Neoplasm & $94(0.5)$ & $9(0.2)$ & $5(0.1)$ & $9(0.2)$ \\
\hline Pancreatitis & $166(1.0)$ & $10(0.3)$ & $8(0.2)$ & $10(0.3)$ \\
\hline Pneumonia & $691(4.0)$ & $97(2.4)$ & $95(2.6)$ & $97(2.6)$ \\
\hline Respiratory Failure & $991(5.7)$ & $238(6.0)$ & $243(6.5)$ & $237(6.4)$ \\
\hline Sepsis & $1409(8.1)$ & $249(6.2)$ & $261(7.0)$ & $249(6.7)$ \\
\hline Tachycardia & $48(0.3)$ & $23(0.6)$ & $22(0.6)$ & $22(0.6)$ \\
\hline Vavular Disease & $878(5.0)$ & $544(13.6)$ & $468(12.6)$ & $484(13.0)$ \\
\hline \multicolumn{5}{|c|}{$\begin{array}{l}\text { Continuous variables are presented as mean (standard deviation), categorical as frequency } \\
\text { (percentage). T-test was used to compare statin recipients vs non-statin for continuous variables, } \\
\text { Fisher's exact test for categorical variables. Standardized differences (SD) are defined as the } \\
\text { difference in means, proportions or ranks divided by the mutual standard deviation. }\end{array}$} \\
\hline \multicolumn{5}{|c|}{$\left.{ }^{(}\right)$variables were used for the calculation of propensity scores. } \\
\hline $\begin{array}{l}\text { Abbreviations:LOS: length } \\
\text { Organ Failure Assessmen }\end{array}$ & $\begin{array}{l}\text { stay; OASI } \\
\text { APSII: Simp }\end{array}$ & $\begin{array}{l}\text { xford Acl } \\
\text { ed Acute }\end{array}$ & $\begin{array}{l}\text { Illness Sc } \\
\text { ore II. }\end{array}$ & SOFA: Sequential \\
\hline
\end{tabular}

\section{The primary outcome}

The Kaplan-Meier analysis showed that statin users had a better 28-day and in hospital survival curve than the non-users in unmatched and matched cohorts. The Cox model showed that the use of statins before or during ventilation was associated with an improved 28-day survival in both the overall cohort (HR 0.85 95\% Cl $0.80 \sim 0.90$ Fig. 2A) and the matched cohort (HR 0.72 95\% Cl $0.67 \sim 0.77$ Fig. 2B). Statin use was also associated with improved in-hospital survival in the overall cohort (HR 0.90,95\% $\mathrm{Cl} 0.85 \sim$ 0.95 Fig. 2C) and the matched cohort (HR 0.72 95\% Cl $0.67 \sim 0.77$ Fig. 2D). In the multivariate Cox model, the use of statins was associated with a beneficial effect on 28-day survival in the unmatched cohort (HR $0.7395 \% \mathrm{Cl} 0.68 \sim 0.77$ Table 2 ) and the matched cohort (HR $0.7395 \% \mathrm{Cl} 0.68 \sim 0.78$ Table 2). 
Table 2

Cox regression model of 28 days mortality in the unmatched and matched cohorts

\begin{tabular}{|c|c|c|c|c|}
\hline & Unmatched cohor & & Matched cohort & \\
\hline Variables & $\mathrm{HR}[95 \% \mathrm{Cl}]$ & $\mathrm{p}$-value & $\mathrm{HR}[95 \% \mathrm{Cl}]$ & p-value \\
\hline Statin Use & $0.73[0.68,0.77]$ & $<0.001$ & $0.73[0.68,0.79]$ & $<0.001$ \\
\hline Age & $1.03[1.02,1.03]$ & $<0.001$ & $1.03[1.02,1.03]$ & $<0.001$ \\
\hline Gender $=$ Male & $1.00[0.96,1.04]$ & 0.978 & $1.00[0.93,1.08]$ & 0.923 \\
\hline SAPSII & $1.01[1.01,1.01]$ & $<0.001$ & $1.01[1.01,1.01]$ & $<0.001$ \\
\hline Liver disease & $1.02[0.95,1.10]$ & 0.567 & $1.11[0.90,1.38]$ & 0.322 \\
\hline Renal failure & $0.99[0.93,1.05]$ & 0.75 & $1.02[0.93,1.12]$ & 0.639 \\
\hline Diabetes uncomplicated & $1.10[1.04,1.15]$ & 0.001 & $1.15[1.06,1.24]$ & 0.001 \\
\hline Diabetes complicated & $1.08[0.99,1.17]$ & 0.077 & $1.10[0.98,1.25]$ & 0.106 \\
\hline Coronary & $0.99[0.92,1.06]$ & 0.79 & $1.01[0.93,1.10]$ & 0.818 \\
\hline Obesity & $0.75[0.68,0.83]$ & $<0.001$ & $0.77[0.67,0.89]$ & $<0.001$ \\
\hline Cerebral Infarction & $1.68[1.47,1.93]$ & $<0.001$ & $1.50[1.26,1.78]$ & $<0.001$ \\
\hline Hypertension & $0.98[0.93,1.02]$ & 0.294 & $0.94[0.87,1.02]$ & 0.136 \\
\hline Congestive heart failure & $0.97[0.93,1.02]$ & 0.217 & $1.04[0.96,1.12]$ & 0.343 \\
\hline Cardiac arrhythmias & $0.83[0.80,0.87]$ & $<0.001$ & $0.85[0.79,0.92]$ & $<0.001$ \\
\hline Other neurological & $1.07[1.01,1.13]$ & 0.02 & $1.05[0.94,1.16]$ & 0.378 \\
\hline Chronic pulmonary & $1.24[1.18,1.30]$ & $<0.001$ & $1.29[1.19,1.40]$ & $<0.001$ \\
\hline Alcohol abuse & $0.89[0.81,0.97]$ & 0.012 & $0.97[0.78,1.21]$ & 0.811 \\
\hline
\end{tabular}

\section{Secondary outcomes and plasma biomarkers}

The secondary outcomes included ICU LOS, hospital LOS, VFDs and MELD score. After matching, statin use was associated with longer ICU LOS (6.83 \pm 8.40 vs $6.04 \pm 7.57)$, shorter hospital LOS $(12.37 \pm 10.96$ vs. $12.46 \pm 11.91)$, fewer VFDs ( $24.34 \pm 5.94$ vs $24.84 \pm 5.53)$ and lower MELD score (14.25 \pm 6.91 vs. $15.34 \pm 7.79)$. We compared users of different types of statins to nonusers by Cox regression model. In the Cox model, all statins improved the survival of ventilated patients. Atorvastatin + simvastatin seemed to be associated with the best outcome (HR $0.4295 \% \mathrm{Cl} 0.30 \sim 0.60$ ), followed by rosuvastatin (HR 0.52 $95 \% \mathrm{Cl} 0.36 \sim 0.73$ ), pravastatin (HR $0.6595 \% \mathrm{Cl} 0.50 \sim 0.84$ ) and simvastatin (HR $0.6695 \% \mathrm{Cl} 0.59$ 
0.74). The least-effective statin was atorvastatin, which was associated with a decreased 28-day mortality (HR $0.8195 \% \mathrm{Cl} 0.74 \sim 0.88$ ). After adjusting for confounders, all the statins still resulted in significant improvement in survival compared to nonuse based on this survival function.

Regarding the biomarkers, we found no large differences in the matched cohort. Additionally, we found that statin use was not associated with higher aspartate aminotransferase (AST) or alanine aminotransferase (ALT) levels after matching (Fig. 3).

\section{Subgroup analysis}

In the subgroup analysis, we found that statins had a protective effect in most of the subgroups but not in individuals with liver disease or obesity. More importantly, statin use showed no effect in inflammationrelated groups, such as the septicemia, respiratory failure and pneumonia subgroups (Fig. 4). In the current study, patients with coronary disease accounted for a large proportion of the sample. However, in the noncoronary artery disease subgroup, we also found that statin use was associated with reduced mortality.

\section{Discussion}

Lung injury remains one of the major complications of mechanical ventilation in the ICU. This injury could result from an altered host immune response after mechanical stretch [3]. Using statin therapy to protect patients with lung injury could therefore be a reasonable strategy, as these drugs could abate the host inflammatory response to infection [21], especially within the lungs [6]. This study revealed that statin use was associated with improved 28-day survival and in-hospital survival. All kinds of statins showed reduced HRs. This evidence might indicate the protective effect of statins in ventilation patients. In the subgroup analyses, we found that statins had a protective effect in most of the subgroups but not in the septicemia, acute respiratory failure or pneumonia subgroups. All these results might explain the protective effect of statins.

In addition to lowering cholesterol, statins exert pleiotropic effects [6-9] such as anti-inflammatory, antioxidant, and immunomodulatory effects, especially in the context of pulmonary disorders [22]. Statins may reduce COPD exacerbation [23]. Statins have also been suggested to be effective in patients with acute lung injury or acute respiratory distress syndrome in some observational studies [24, 25]. These clinical effects may be mediated by a reduction in pulmonary and systemic inflammation. Simvastatin decreased bronchoalveolar lavage IL-8 by 2.5 -fold $(P=0.04)$ [26]. Statins also showed a protective effect against sepsis. When compared with nonusers, simvastatin (HR, 0.72; $95 \% \mathrm{Cl}, 0.58-$ $0.90)$ and atorvastatin $(\mathrm{HR}, 0.78 ; 95 \% \mathrm{Cl}, 0.68-0.90)$ users had improved 30-day survival [13]. The current study examined the anti-inflammatory effect of statins from a ventilation patient cohort, which has not been previously reported. A recent study showed that infections in older adults were associated with prolonged, impaired neutrophil migration. Simvastatin improves neutrophil migration in vivo in healthy 
individuals and in vitro in milder infective events but not in severe sepsis, supporting its potential utility as an early intervention during pulmonary infections $[27,28]$.

Animal models may have further explained the protective effect of statins against lung injury. Statins increase glucocorticoid receptor expression in alveolar macrophages and downregulate NF-KB activation associated with the increased number of alveolar macrophages [15]. Two other animal models of lung injury induced by mechanical ventilation also support these findings $[16,17]$. The protective effect may be due to the anti-inflammatory effect of statins. Prior statin use was associated with a lower baseline IL6 concentration, and continuation of atorvastatin treatment in this cohort was associated with improved survival [29]. Statins have been shown to reduce vascular leakage and inflammation in animal models of lung injury [30]. Statins may also attenuate lung injury by downregulating the expression of inflammatory cytokines [31, 32]. Our previous study revealed the lung-protective effect of statins caused by the reduction of inflammatory cell infiltration [33]. Additionally, statins may have direct antibacterial effects and modulate bacterial virulence [34-36]. Sarah et al. showed that prior exposure to physiological nanomolar serum concentrations of simvastatin confers significant cellular resistance to the cytotoxicity of pneumolysin, which revealed how statins contribute to the reduced pathology observed in the context of pneumonia and other bacterial infections [37].

The subgroup analyses showed that statins had no efficacy in the context of pneumonia, septicemia or acute respiratory failure. However, this difference might be explained by the fact that statins may exert an inflammatory protective effect only for mild-to-moderate pulmonary infectious disease. From this point of view, the subgroup analyses explained why evidence of the efficacy of statins against sepsis and ARDS is controversial. In a randomized controlled trial (RCT) with a follow-up of over one year, there was no significant difference in cumulative survival between the rosuvastatin and placebo groups ( $58 \%$ vs $61 \%$; $p=0.377$ ) [38]. Simvastatin therapy was not significantly associated with the difference between the study groups in mortality at 28 days $(22.0 \%$ and $26.8 \% ; P=0.23)$ among patients with ARDS [39]. However, the effect of statins on ventilation-induced lung injury was minimal. Recently, a group of "hyperinflammatory" ARDS patients showed a benefit from statin treatment [40]. Sapey stated that statins may improve neutrophil migration and may have protective effects in milder infective events but not in severe sepsis or ARDS [27]. The underlying reason for this controversial evidence might be that statins may have immune modulatory effects in only milder diseases instead of in intensive inflammatory diseases such as ARDS. However, we might need new RCTs exploring the effects on mild infectious diseases such as ventilation-induced lung injury to prove this hypothesis.

Several limitations must be disclosed in the current study. The main limitation of this study was that the observational nature without randomization precludes a definite conclusion regarding statin benefits. However, a randomized controlled trial on the effect of long-term statin treatment on the outcome of patients on ventilation would require many participants. To explore the effect of statins on patients on ventilation, observational data may currently remain the best available evidence. Second, because of the retrospective design of this study, patient selection bias may be inevitable. Third, the missing data of potential confounders was a limitation that could not be overcome. Our findings should thus be 
interpreted with caution. Additionally, only white blood cell (WBC) measurements were analyzed for inflammation assessment. Regarding the host response, the assessment of inflammatory cytokines might provide different insights. The relationships of the dose and treatment duration of statins with survival were not analyzed here because we included different types of statins, and the doses of the different statins were not comparable. Finally, we included ventilation patients with different diagnoses. Even with subgroup analyses, we cannot conclude that statins are specifically effective in a specific population.

\section{Conclusion}

Our study suggests that the use of statins may be associated with reduced mortality in ventilated patients. The favorable effects of statins correlate with their anti-inflammatory effects. Further studies in different populations or RCTs are needed to validate our findings.

\section{Abbreviations}

MIMIC-III:Medical Information Mart for Intensive Care III ; LOS:length of stay; length of stay; VFDs:ventilator-free days; MELD:model for end-stage liver disease score; ARDS:acute respiratory distress syndrome; VAP:ventilator-associated pneumonia; ICU:intensive care unit ; IRB:institutional review board; SAPSII:Simplified Acute Physiology Score Il; Cl:confidence interval (CI); SDs:standard deviations ; HR:Hazard Ratio; AST:aminotransferase; ALT:alanine aminotransferase; RCT:randomized controlled trial; WBC:white blood cell.

\section{Declarations}

Ethics approval and consent to participate:

The requirement for institutional review board (IRB) approval from our institution was exempted because MIMIC-III is a third-party anonymized publicly available database with pre-existing IRB approval.

Consent for publication

Not applicable

Availability of data and materials

The datasets used and/or analysed during the current study are available from the corresponding author on reasonable request.

Competing interests

The authors declare that they have no competing interests.

Funding 
Sponsored by the Interdisciplinary Program of Shanghai Jiao Tong University (Project Number 06N1801046). Additionally sponsored by Clinical Research Innovation Plan of Shanghai General Hospital (Project Number CTCCR-2018C10)

Authors' contributions

LQ write the manuscript and collect the data from database. CD collect the data from MIMIC database, washed the data and did the statistical analysis. MC contributed to data collecting and data analysis of this work. XY contributed to the data collecting and analysis of this work. HY contributed to the data collecting work. WL contributed to the data collecting work. GF contributed to the data collecting work. XJ contributed to the data collecting and literature research of this work. KM contributed to the statistic work of this study. TR contributed to the study design and paper revising. ZY contributed to the data collecting of this work. ZH contributed to the data collecting of this work. WR designed this research, revised the manuscript and analyzed the data. Du, Jiang designed this research, write the manuscript, analyzed the data and drew all the figures in this study. All authors read and approved the final manuscript.

Acknowledgements

Not applicable

\section{References}

1. Wunsch H, Linde-Zwirble WT, Angus DC, Hartman ME, Milbrandt EB, Kahn JM: The epidemiology of mechanical ventilation use in the United States. Crit Care Med 2010, 38(10):1947-1953.

2. Tobin MJ: Mechanical ventilation. New England Journal of Medicine 1994, 330(15):1056-1061.

3. Charles PE, Tissieres P, Barbar SD, Croisier D, Dufour J, Dunn-Siegrist I, Chavanet P, Pugin J: Mildstretch mechanical ventilation upregulates toll-like receptor 2 and sensitizes the lung to bacterial lipopeptide. Crit Care 2011, 15(4):R181.

4. Willeit P, Ridker PM, Nestel PJ, Simes J, Tonkin AM, Pedersen TR, Schwartz GG, Olsson AG, Colhoun $\mathrm{HM}$, Kronenberg $\mathrm{F}$ et al: Baseline and on-statin treatment lipoprotein(a) levels for prediction of cardiovascular events: indiv idual patient-data meta-analysis of statin outcome trials. Lancet 2018, 392(10155):1311-1320.

5. Cohen JS: Statin therapy after stroke or transient ischemic attack. N Engl J Med 2006, 355(22):2368; author reply 2370-2361.

6. Krishna RK, Issa O, Saha D, Macedo FY, Correal B, Santana O: Pleiotropic effects of the 3-hydroxy-3methylglutaryl-CoA reductase inhibitors in pulmonary diseases: a comprehensive review. Pulmonary pharmacology \& therapeutics 2015, 30:134-140.

7. Liao JK, Oesterle A: The Pleiotropic Effects of Statins - From Coronary Artery Disease and Stroke to Atrial Fibrillation a nd Ventricular Tachyarrhythmia. Curr Vasc Pharmacol 2018. 
8. Mihos CG, Santana O: Pleiotropic effects of the HMG-CoA reductase inhibitors. Int J Gen Med 2011, 4:261-271.

9. Rohilla A, Rohilla S, Kumar A, Khan MU, Deep A: Pleiotropic effects of statins: A boulevard to cardioprotection. Arabian Journal of Chemistry 2016, 9:S21-S27.

10. Terblanche M, Almog Y, Rosenson RS, Smith TS, Hackam DG: Statins and sepsis: multiple modifications at multiple levels. Lancet Infect Dis 2007, 7(5):358-368.

11. Nielsen AG, Nielsen RB, Riis AH, Johnsen SP, Sørensen HT, Thomsen RW: The impact of statin use on pneumonia risk and outcome: a combined population-based case-control and cohort study. Critical care 2012, 16(4):R122.

12. Al Harbi SA, Tamim HM, Arabi YM: Association between statin therapy and outcomes in critically ill patients: a nested cohort study. BMC Clin Pharmacol 2011, 11:12.

13. Lee CC, Lee MG, Hsu TC, Porta L, Chang SS, Yo CH, Tsai KC, Lee M: A Population-Based Cohort Study on the Drug-Specific Effect of Statins on Sepsis Outcome. Chest 2017.

14. Wan YD, Sun TW, Kan QC, Guan FX, Zhang SG: Effect of statin therapy on mortality from infection and sepsis: a meta-analysis of randomized and ob servational studies. Crit Care 2014, 18(2):R71.

15. Takano K, Yamamoto S, Tomita K, Takashina M, Yokoo H, Matsuda N, Takano Y, Hattori Y: Successful treatment of acute lung injury with pitavastatin in septic mice: potential role of glucoco rticoid receptor expression in alveolar macrophages. J Pharmacol Exp Ther 2011, 336(2):381-390.

16. M®rller HC, Hellwig K, Rosseau S, Tschernig T, Schmiedl A, Gutbier B, Schmeck B, Hippenstiel S, Peters $\mathrm{H}$, Morawietz $\mathrm{L}$ et al: Simvastatin attenuates ventilator-induced lung injury in mice. Crit Care 2010, 14(4):R143.

17. Siempos, II, Maniatis NA, Kopterides P, Magkou C, Glynos C, Roussos C, Armaganidis A: Pretreatment with atorvastatin attenuates lung injury caused by high-stretch mechanical ventilation i $\mathrm{n}$ an isolated rabbit lung model. Crit Care Med 2010, 38(5):1321-1328.

18. Johnson AE, Pollard TJ, Shen L, Lehman LW, Feng M, Ghassemi M, Moody B, Szolovits P, Celi LA, Mark RG: MIMIC-III, a freely accessible critical care database. Sci Data 2016, 3:160035.

19. Kamat SA, Gandhi SK, Davidson M: Comparative effectiveness of rosuvastatin versus other statin therapies in patients at increased risk of failure to achieve low-density lipoprotein goals. Curr Med Res Opin 2007, 23(5):1121-1130.

20. Masadeh M, Mhaidat N, Alzoubi K, Al-Azzam S, Alnasser Z: Antibacterial activity of statins: a comparative study of atorvastatin, simvastatin, and rosuvastatin. Ann Clin Microbiol Antimicrob 2012, 11:13.

21. Tleyjeh IM, Kashour T, Hakim FA, Zimmerman VA, Erwin PJ, Sutton AJ, Ibrahim T: Statins for the prevention and treatment of infections: a systematic review and meta-analysis. Arch Intern Med 2009, 169(18):1658-1667.

22. Chopra V, Flanders SA: Does Statin Use Improve Pneumonia Outcomes? Chest 2009, 136(5):13811388. 
23. Blamoun Al, Batty GN, DeBari VA, Rashid AO, Sheikh M, Khan MA: Statins may reduce episodes of exacerbation and the requirement for intubation in patients with COPD: evidence from a retrospective cohort study. International journal of clinical practice 2008, 62(9):1373-1378.

24. O'Neal HR, Koyama T, Koehler EAS, Siew E, Curtis BR, Fremont RD, May AK, Bernard GR, Ware LB: Prehospital statin and aspirin use and the prevalence of severe sepsis and acute lung injury/acute respiratory distress syndrome. Critical Care Medicine 2011, 39(6):1343-1350.

25. Mansur A, Steinau M, Popov AF, Ghadimi M, Beissbarth T, Bauer M, Hinz J: Impact of statin therapy on mortality in patients with sepsis-associated acute respiratory distress syndrome (ARDS) depends on ARDS severity: a prospective observational cohort study. Bmc Med 2015, 13.

26. Craig TR, Duffy MJ, Shyamsundar M, McDowell C, O'Kane CM, Elborn JS, McAuley DF: A randomized clinical trial of hydroxymethylglutaryl- coenzyme a reductase inhibition for acute lung injury (The HARP Study). American journal of respiratory and critical care medicine 2011, 183(5):620-626.

27. Sapey E, Patel JM, Greenwood HL, Walton GM, Hazeldine J, Sadhra C, Parekh D, Dancer RCA, Nightingale P, Lord JM et al: Pulmonary Infections in the Elderly Lead to Impaired Neutrophil Targeting, Which Is Improved by Simvastatin. Am J Respir Crit Care Med 2017, 196(10):1325-1336.

28. Sapey E, Patel JM, Greenwood H, Walton GM, Grudzinska F, Parekh D, Mahida RY, Dancer RC, Lugg ST, Howells PA et al: Simvastatin Improves Neutrophil Function and Clinical Outcomes in Pneumonia: a Pilot Randomised Contr olled Trial. Am J Respir Crit Care Med 2019.

29. Kruger P, Bailey M, Bellomo R, Cooper DJ, Harward M, Higgins A, Howe B, Jones D, Joyce C, Kostner K et al: A multicenter randomized trial of atorvastatin therapy in intensive care patients with severe sepsis. Medicine 2013, 187(7):743-750.

30. Jacobson JR, Barnard JW, Grigoryev DN, Ma SF, Tuder RM, Garcia JG: Simvastatin attenuates vascular leak and inflammation in murine inflammatory lung injury. American Journal of Physiology Lung Cellular \& Molecular Physiology 2005, 288(6):1026-1032.

31. Melo AC, Valenca SS, Gitirana LB, Santos JC, Ribeiro ML, Machado MN, Magalhaes CB, Zin WA, Porto LC: Redox markers and inflammation are differentially affected by atorvastatin, pravastatin or simvastatin administered before endotoxin-induced acute lung injury. International immunopharmacology 2013, 17(1):57-64.

32. Shyamsundar M, Mckeown STW, O'Kane CM, Craig TR, Brown V, Thickett DR, Matthay MA, Taggart CC, Backman JT, Elborn JS: Simvastatin Decreases Lipopolysaccharide-induced Pulmonary Inflammation in Healthy Volunteers. American Journal of Respiratory \& Critical Care Medicine 2009, 179(12):1107-1114.

33. Du J, Zhu Y, Meng X, Xie H, Wang J, Zhou Z, Wang R: Atorvastatin attenuates paraquat poisoninginduced epithelial-mesenchymal transition via downregulating hypoxia-inducible factor-1 alpha. Life Sciences.

34. Hennessy E, Adams C, Reen FJ, O'Gara F: Is There Potential for Repurposing Statins as Novel Antimicrobials? Antimicrob Agents Chemother 2016, 60(9):5111-5121. 
35. Ting M, Whitaker EJ, Albandar JM: Systematic review of the in vitro effects of statins on oral and perioral microorganisms. Eur J Oral Sci 2016, 124(1):4-10.

36. Ribeiro NQ, Costa MC, Magalh?es TFF, Carneiro HCS, Oliveira LV, Fontes ACL, Santos JRA, Ferreira GF, Araujo GRS, Alves $V$ et al: Atorvastatin as a promising anticryptococcal agent. Int $J$ Antimicrob Agents 2017, 49(6):695-702.

37. Statt S, Ruan JW, Hung LY, Chang CY, Huang CT, Lim JH, Li JD, Wu R, Kao CY: Statin-conferred enhanced cellular resistance against bacterial pore-forming toxins in airway epithelial cells. $A m \mathrm{~J}$ Respir Cell Mol Biol 2015, 53(5):689-702.

38. Dinglas VD, Hopkins RO, Wozniak AW, Hough CL, Morris PE, Jackson JC, Mendez-Tellez PA, Bienvenu $\mathrm{OJ}$, Ely EW, Colantuoni E et al: One-year outcomes of rosuvastatin versus placebo in sepsisassociated acute respiratory distress syndrome: prospective follow-up of SAILS randomised trial. Thorax 2016, 71(5):401-410.

39. McAuley DF, Laffey JG, O'Kane CM, Perkins GD, Mullan B, Trinder TJ, Johnston P, Hopkins PA, Johnston AJ, McDowell C et al: Simvastatin in the acute respiratory distress syndrome. The New England journal of medicine 2014, 371(18):1695-1703.

40. Calfee CS, Delucchi KL, Sinha P, Matthay MA, Hackett J, Shankar-Hari M, McDowell C, Laffey JG, O'Kane CM, McAuley DF et al: Acute respiratory distress syndrome subphenotypes and differential response to simvastatin: secondary analysis of a randomised controlled trial. Lancet Respir Med 2018, 6(9):691-698.

\section{Figures}




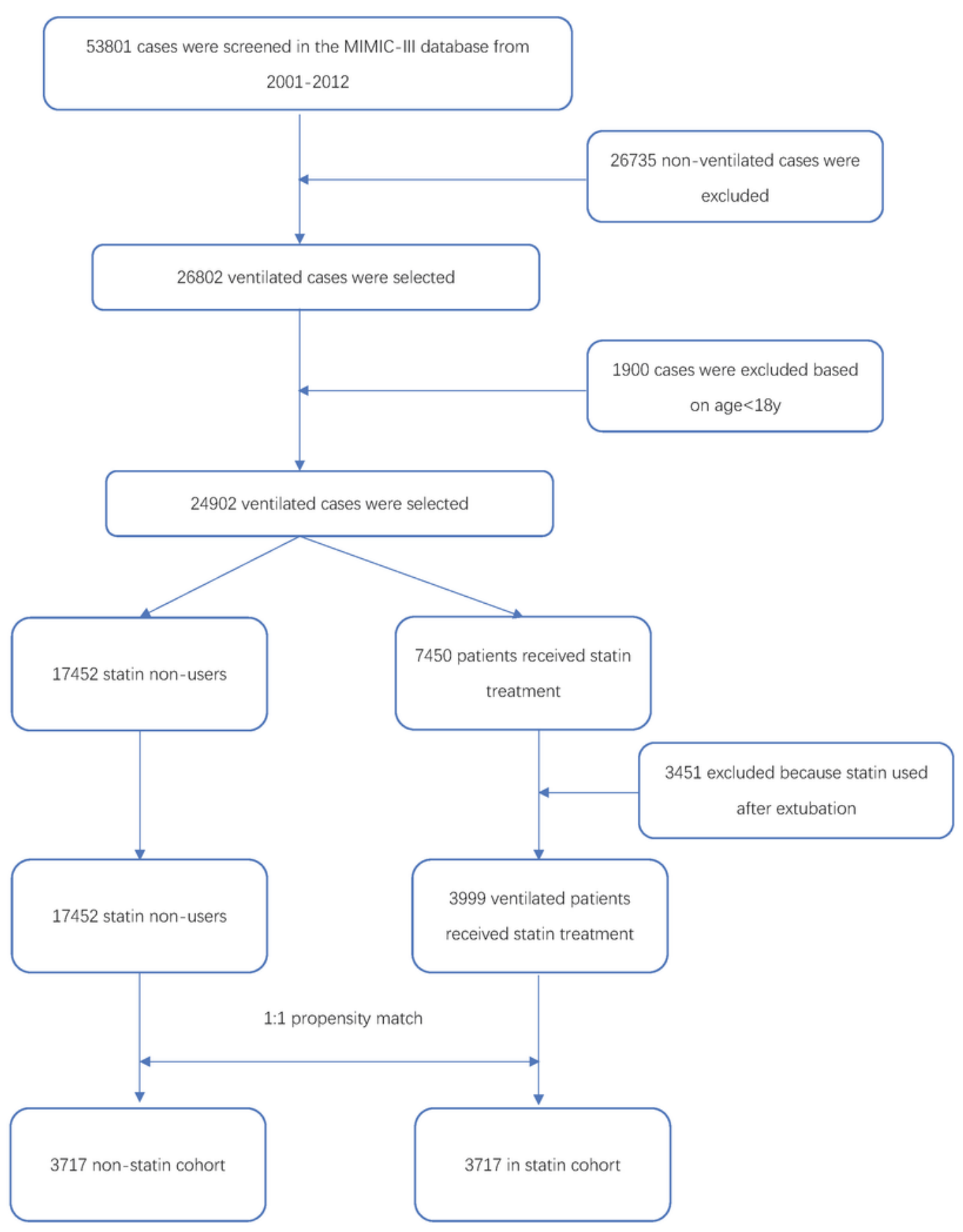

Figure 1

Flowchart of cohort building. 

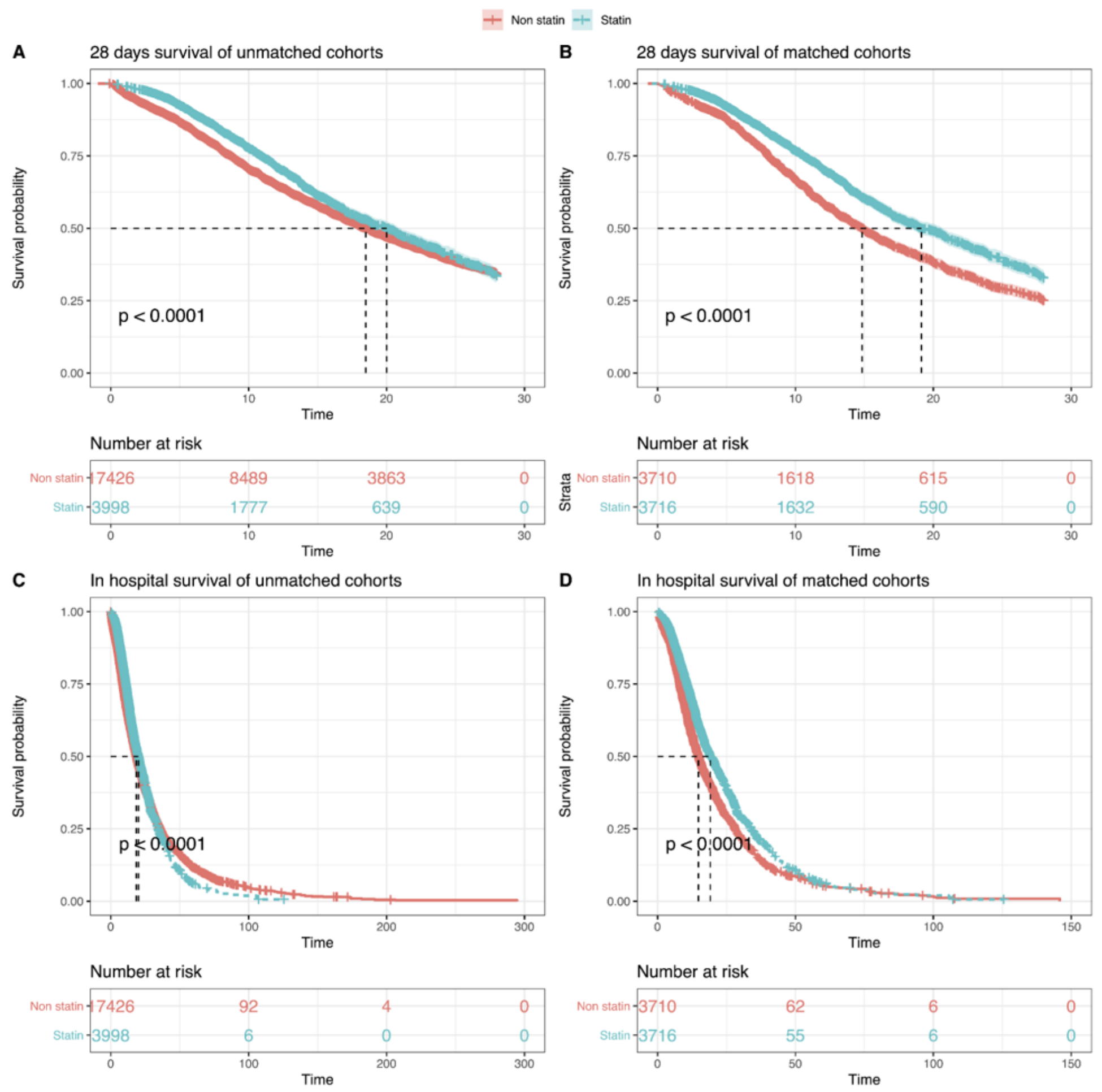

\section{Figure 2}

Kaplan-Meier curves for all-cause mortality in statin recipients vs. nonrecipients in the unmatched cohorts and propensity score-matched cohorts. A: Statin use was associated with improved 28 -day survival in the unmatched cohort (HR 0.85 95\% Cl 0.80 0.90); B: Statin use was associated with improved 28-day survival in the matched cohort (HR $0.7295 \% \mathrm{Cl} 0.67 \sim 0.77$ ); C: Statin use was associated with improved in-hospital survival in the unmatched cohort (HR 0.90, 95\% Cl 0.85 0.95); D: Statin use was associated with improved in-hospital survival in the matched cohort (HR $0.7595 \% \mathrm{Cl} 0.70 \sim 0.80$ ). 

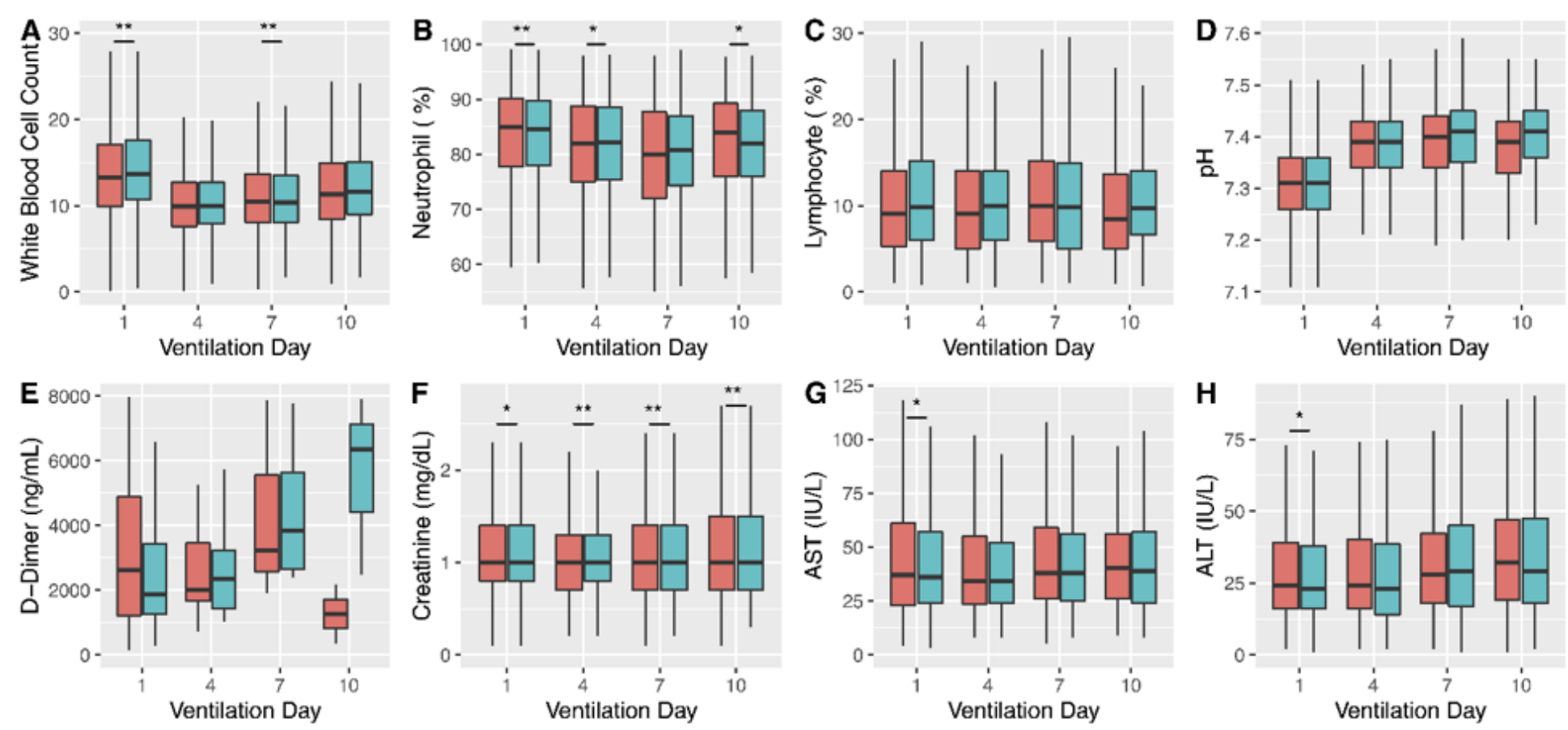

Statin 它 Non_Statin 它 Statin

Figure 3

The plasma biomarkers during the first ten ventilation days. Day 1 was the first day of ventilation; *: $p<0.05 ; * *: p<0.01$. 


\section{Subgroups}

Age $>65$ YES

NO

Pneumonia YES

NO

Sepsis YES

NO

Resfailure YES

NO

Coronary disease YES

$$
\text { NO }
$$

Ischemic stroke YES

NO

Congestive heart failure YES

NO

Valvular disease YES

NO

Chronic pulmonary YES

NO

Diabetes uncomplicated YES

NO

Diabetes complicated YES

NO

Hypertension YES

NO

Renal failure YES

NO

Liver disease YES

NO

Obesity YES

NO

Total
Sample Size HR $95 \% \mathrm{Cl}$ lower $95 \% \mathrm{Cl}$ upper p-value

4961

0.76

2469

0.83

$209 \quad 0.99$

$7221 \quad 0.76$

$517 \quad 1.05$

$6913 \quad 0.74$

$478 \quad 1.21$

$6952 \quad 0.73$

$2357 \quad 0.55$

$5073 \quad 0.84$

$238 \quad 0.59$

$7192 \quad 0.78$

$3153 \quad 0.82$

$4277 \quad 0.7$

$2198 \quad 0.64$

$5232 \quad 0.81$

18120.82

$5618 \quad 0.75$

$2152 \quad 0.74$

$5278 \quad 0.78$

$\begin{array}{ll}721 & 0.77\end{array}$

$6709 \quad 0.77$

$5360 \quad 0.72$

$2070 \quad 0.87$

$1400 \quad 0.87$

$6030 \quad 0.74$

$209 \quad 0.66$

$7221 \quad 0.77$

$730 \quad 0.79$

$6700 \quad 0.77$

$\begin{array}{ll}7430 & 0.77\end{array}$

$0.96 \quad 0.01$
0.71

0.72

0.71

0.71

0.85

$0.82<0.01$

$\begin{array}{ll}1.38 & 0.97\end{array}$

$0.81<0.01$

$1.3 \quad 0.63$

$0.8<0.01$

$1.51 \quad 0.09$

$0.79<0.01$

$0.64<0.01 \vdash \neg$

$0.91<0.01 \quad \vdash \dashv$

$0.81<0.01 \longmapsto \longrightarrow$

$0.83<0.01 \quad$

0.72

0.75

0.64

0.56

0.75

0.73

0.69

0.65

0.72

0.64

0.71

0.67

0.77

0.76

0.68

0.46

0.72

0.61

0.71

0.72
$0.9<0.01$

$0.78<0.01$

$0.73<0.01$

$0.88<0.01$

$0.93<0.01$

$0.81<0.01$

$0.84<0.01$

$0.85<0.01$

$0.94<0.01$

$0.82<0.01$

$0.78<0.01$

$0.98 \quad 0.02$

$1 \quad 0.04$

$0.8<0.01$

$0.94 \quad 0.02$

$0.83<0.01$

$1.02 \quad 0.07$

$0.82<0.01$

$0.82<0.01$
$+-1$

$\vdash \multimap$

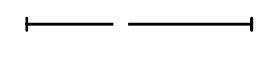

$\vdash \dashv$

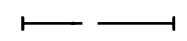

$+-1$

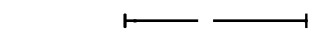

$+-1$

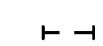

$\vdash-1$

$\vdash \dashv$

$+-1$

$\vdash \rightarrow$

$1-1$

$\vdash \neg$

$r-1$

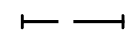

$t+$

$+-1$

$\vdash \longrightarrow$

$\vdash \multimap$
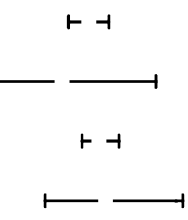

$\vdash \dashv$

Figure 4

The forest plot of statins in the 28-day survival subgroup analyses. 